\section{AB1001 MANAGEMENT OF GLUCOCORTICOID-INDUCED OSTEOPOROSIS IN RHEUMATOID ARTHRITIS: THE EXAMPLE OF THE "RIC NORD DE FRANCE” COHORT}

J. Corli ${ }^{1}$, G. Baudens ${ }^{2}$, R.-M. Flipo ${ }^{1}$, B. Cortet ${ }^{1}$, on behalf of RIC-Nord de France. ${ }^{1}$ Rheumatology, CHRU Lille, Lille; ${ }^{2}$ Rheumatology, Valenciennes, Valenciennes, France

Background: Glucocorticoid-induced osteoporosis (GIOP) is the most common cause of secondary osteoporosis. Patients followed for Rheumatoid Arthritis (RA) are particularly exposed to OP and have a greater risk of fracture, which must be prevented. The newest French guidelines for GIOP management were published in 2014 and it is not known yet how they are applied in real life.

Objectives: The objective of our study was to investigate the treatment of glucocorticoid-induced osteoporosis in the Rhumatismes Inflammatoires Chroniques Nord de France (formerly known as RIC-NPC) network in 2016 for patients with rheumatoid arthritis (RA)

Methods: In this observational study, the patients studied were followed in the RIC network for RA from 2004 until June 2016, had at least one bone mineral density (BMD) assessment and glucocorticoid therapy during follow-up. Demographic characteristics of patients, BMD results, fractures and treatments implemented were collected from network data completed during consultations by practitioners. Results: 647 patients were enrolled, including 511 women (79\%). The average age of patients was 65.5 years $(S D=12)$ with a mean DAS28 of $3.91(S D=1.44)$, mean dose of steroid of $7.6 \mathrm{mg}(\mathrm{SD}=6.6)$ and a mean duration of treatment of 49 months $(S D=53.7)$. The average $T$-score at the first $B M D$ assessment was -0.99 at the spine and -1.03 at the total hip. 298 patients received an anti-osteoporotic treatment $(46 \%)$. Treated patients were older $(p<0.0001)$, with lower weight $(p=0.001)$ and had a lower T-score at both the spine and the total hip $(p<0.0001$ for both sites). They most often underwent a prior fracture $(p<0.0001)$, and an initial T-score less than $-1.5 \mathrm{SD}(\mathrm{p}<0.0001)$

Conclusions: Our study has the advantage of reflecting the management of GIOP in a "real life" cohort. Almost half of our patients followed for RA who received corticosteroids had received treatment. According to French guidelines the number of patients requiring an anti-osteoporotic treatment should be higher.

\section{REFERENCES:}

[1] Briot K, Cortet B, Roux C, et al. 2014 update of recommendations on the prevention and treatment of glucocorticoid-induced osteoporosis. Joint Bone Spine 2014;81:493-501.

[2] Kok C, Sambrook PN. Secondary osteoporosis in patients with an osteoporotic fracture. Best Pract Res Clin Rheumatol 2009;23:769-79.

[3] Wibaux C, Baudens G, Cortet B, et al. Évaluation de la prise en charge de l'ostéoporose cortico-induite chez les patientes du réseau RIC-Nord-Pasde-Calais. Rev Rhum 2007;74:1035

Disclosure of Interest: J. Corli Grant/research support from: Amgen, G. Baudens Grant/research support from: Amgen, R.-M. Flipo: None declared, B. Cortet Grant/research support from: Amgen

DOI: 10.1136/annrheumdis-2018-eular.2673

\section{AB1002 DIFFERENCES IN BONE METABOLISM BETWEEN INTERMITTENT AND CONTINUOUS TREATMENT WITH LHRH AGONISTS IN PROSTATE CANCER PATIENTS}

K.R. Arevalo ${ }^{1,1}$, J. Ivorra ${ }^{1}$, C. Vera ${ }^{2}$, E. Grau ${ }^{1}$, I. Chalmeta ${ }^{1}$, L. Gonzalez ${ }^{1}$, R. Negueroles ${ }^{1}$, C. Alcañiz ${ }^{1}$, I. Canovas ${ }^{1}$, C. Feced ${ }^{1}$, J.J. Fragio ${ }^{1}$, R. Gonzalez ${ }^{1}$, E. Labrador ${ }^{1}$, I. Martinez ${ }^{1}$, C. Najera ${ }^{1}$, J.E. Oller ${ }^{1}$, F.M. Ortiz ${ }^{1}$, E. Vicens ${ }^{1}$, M. De la Rubia $^{1}$, D. Hervas ${ }^{3}$, J.A. Roman ${ }^{1} .{ }^{1}$ Rheumatology Department, ${ }^{2}$ Urology Department, HUP La Fe; ${ }^{3}$ Biostatistical Unit, IIS La Fe, Valencia, Spain

Background: Prostate cancer is an hormone dependent neoplasia, therefore androgenic inhibition by $\mathrm{LHRH}$ agonists is the mainstay of treatment. There are different treatment regimen options: continuous or intermittent in order to decrease side effects. As for the bone effects, therapy with LHRH agonists increases bone resorption and decreases bone mineral density (BMD) all together increasing the risk of fracture. The influence of the different treatment regimen in bone metabolism has not been studied enough.

Objectives: To evaluate the effect of the LHRH agonists therapy different regimens on bone metabolism in prostate cancer patients, and whether antiresorptive treatment influences the evolution of BMD according to $\mathrm{LHRH}$ agonists treatment regimen.

Methods: We recruited patients from the Prostate Cancer Protocol of Osteoporotic Risk Assessment in our institution. The patients were evaluated in a basal visit (month 0) and 6-12-18-24 months after basal evaluation. Data of bone metabolism biomarkers, BMD values, LHRH agonists regimen and antiresorptive treatment was collected. Biostatistical analysis with software $\mathrm{R}$ was performed.
Results: We reviewed 69 patients and 52 prostate cancer patients without bone metastasis with 12 months follow up were selected. The mean age at cancer diagnosis was 68.92 (8.44) years old, with a mean Gleason score of $7 .{ }^{1}$

$81 \%$ of patients had LHRH agonists active treatment, $81 \%$ of them were under continuous treatment scheme. $39 \%$ of patients initiated antiresorptive therapy $24 \%$ with intermittent LHRH agonists and $76 \%$ with continuous LHRH agonists. At the basal evaluation $12 \%$ of patients had osteoporosis and the $32 \%$ had osteopenia. $43 \%$ of patients displayed vitD values under $20 \mathrm{ng} / \mathrm{mL}$

Antiresorptive treatment influenced lumbar spine, femoral neck and hip BMD values $(p<0.001)$. In patients with antiresorptive treatment, LHRH agonists intermittent scheme did not have an independent effect in any locations of BMD. In patients without antiresorptive therapy, intermittent $\mathrm{LHRH}$ agonists regimen have a positive effect on BMD in total hip and lumbar spine increasing their values compared to those on continuous LHRH agonists regimen. The effect in lumbar spine depends on the time of the intermittency. LHRH agonist intermittent therapy showed no significant influence on T score values of femoral neck, this effect was independent of antiresorptive therapy. In patients without antiresorptive treatment elevated beta-CTX levels were related to a decrease of BMD values $(p=0.017)$ No fractures were reported during the follow up period.

Conclusions: In our patients there is a high prevalence of vitD deficiency. Antiresortive therapy had a positive effect in the BMD on both $\mathrm{LHRH}$ agonists treatmen schemes. Patients without antiresorptive treatment under an intermittent LHRH agonists scheme display a better evolution in BMD values compared to those under a continuous scheme. In patients without antiresorptive treatment the evolution of BMD values was related to beta-CTX levels during follow up.

Disclosure of Interest: None declared

DOI: 10.1136/annrheumdis-2018-eular.6948

\section{AB1003 USEFULNESS OF DOPPLER ULTRASOUND EXAMINATIONS FOR DETECTING DEEP VENOUS THROMBOSIS DURING THE PERIOPERATIVE PERIOD IN PATIENTS WITH OSTEOPOROTIC FRACTURES OF THE PROXIMAL FEMUR}

K. Nakaseko, N. Mayumi. Department of Orthopaedic Surgery and Rheumatology, KUWANA CITY MEDICAL CENTER, KUwana Mie, Japan

Background: Deep venous thrombosis (DVT) can lead to a venous thromboembolism and increase the risk of a pulmonary thromboembolism (PE). PE is one of the most common causes of death in hospitalised surgical patients.

Although there have been some prospective studies regarding the prevalence of DVT on Doppler ultrasound examinations of the lower extremities, there have no been any prospective studies in which three consecutive Doppler ultrasound examinations were performed to detect DVT during the perioperative period. The purpose of the present study was to prospectively evaluate the occurrence of DVT in patients with osteoporotic fractures of the proximal femur, based on the results of examinations involving three consecutive ultrasound scans. In addition, the usefulness of the d-dimer level as a predictor of DVT was investigated.

Objectives: This study was a single-centre prospective study. One hundred-five patients (18 males and 87 females) between the ages of 46 and 97 years with osteoporotic fractures of the proximal femur were enrolled. All patients were asymptomatic in terms of their clinical DVT findings.

Methods: Three Doppler ultrasound examinations of the lower extremities were conducted in each case: on admission, one day before surgery, and one week after surgery. The period from admission to surgery ranged from 2 to 8 days (mean: 5.4 days). The d-dimer level was measured at one week after surgery and its relationship with the presence/absence of DVT was evaluated by calculating sensitivity, specificity, positive predictive, and negative predictive values.

Results: DVT was detected in 20 patients (2 patients on admission, 9 patients one day before surgery, and 9 patients one week after surgery). The overall prevalence of DVT in the perioperative period was $19.0 \%$ (20/105). As for the characteristics of the patients that did and did not develop DVT, there were no significant differences between the two groups. When the d-dimer cut-off level was set at $4.3 \mu \mathrm{g} / \mathrm{ml}$, the sensitivity and negative predictive value reached $100 \%$, while the specificity was $16.5 \%$, and the positive predictive value was $22.0 \%$. A receiver operating characteristic (ROC) curve was drawn, and the optimal d-dimer cut-off level was examined. The ROC curve was closest to the upper left corner when the d-dimer cut-off level was $12.2 \mu \mathrm{g} / \mathrm{ml}$. At that point, the sensitivity, specificity, positive predictive value, and negative predictive value were $55.0 \%, 69.4 \%, 28.9 \%$, and $86.8 \%$, respectively. 